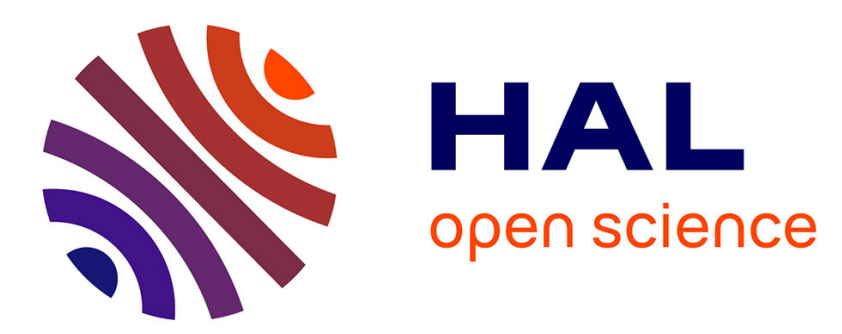

\title{
Language-specific influence on phoneme development: French and Drehu data
}

\author{
Julia Monnin, Hélène Loevenbruck
}

\section{To cite this version:}

Julia Monnin, Hélène Loevenbruck. Language-specific influence on phoneme development: French and Drehu data. Interspeech 2010 - 11th Annual Conference of the International Speech Communication Association, Sep 2010, Makuhari, Japan. pp.1882-1885. hal-00557749

\section{HAL Id: hal-00557749 \\ https://hal.science/hal-00557749}

Submitted on 19 Jan 2011

HAL is a multi-disciplinary open access archive for the deposit and dissemination of scientific research documents, whether they are published or not. The documents may come from teaching and research institutions in France or abroad, or from public or private research centers.
L'archive ouverte pluridisciplinaire HAL, est destinée au dépôt et à la diffusion de documents scientifiques de niveau recherche, publiés ou non, émanant des établissements d'enseignement et de recherche français ou étrangers, des laboratoires publics ou privés. 


\title{
LANGUAGE-SPECIFIC INFLUENCE ON PHONEME DEVELOPMENT: FRENCH AND DREHU DATA
}

\author{
Julia Monnin ${ }^{1,2}$ and Hélène Lovenbruck ${ }^{1}$ \\ ${ }^{1}$ EA CNEP, Université de la Nouvelle-Calédonie, Nouméa, France; ${ }^{2}$ Département Parole et Cognition, GIPSA-lab, \\ CNRS UMR 5216, Université de Grenoble, France; \\ monninjulia@yahoo.fr; Helene.Loevenbruck@gipsa-lab.grenoble-inp.fr \\ http://www.gipsa-lab.inpg.fr
}

\begin{abstract}
This study extends a cross-linguistic collaboration on phonological development, which aims at comparing production of word-initial sequences of consonant-vowel (CVs) across sets of languages which have comparable phonemes that differ in overall frequency or in the frequency with which they occur in analogous sound sequences. By comparing across languages, the influence of language-specific distributional patterns on phoneme mastery can be disentangled from the effects of more general phonetic constraints on development. We made word and non-word repetition experiments with Frenchand Drehu-acquiring two-year-old to five-year-old children. We first analysed production in words according to frequency data in French and Drehu. Results show that productions of word-initial consonants are correlated with their frequencies, especially in younger children. Then we compared the non-word production scores of French- and Drehu-acquiring children. French and Drehu learners have similar mean scores but show different patterns for specific phonemes that differ in frequency.

Keywords: Phonological development, lexical frequency, universal, language-specific, French, Drehu language.
\end{abstract}

\section{INTRODUCTION}

Universal tendencies during phonological development have long been described [1]. Some sounds and sound sequences, considered as «difficult», are acquired later than other sounds which are observed universally in canonical babble, whatever the child's ambient language. For example, sibilant fricatives and affricates are mastered later than stops [2]. Dorsal stops are mastered later when the following vowel is $/ \mathrm{i} /$ as compared to $/ \mathrm{u} /$ [3] Intrasyllabic associations also seem to follow universal tendencies, which have been explained by mandibular oscillations associated with secondary movements of the tongue, velum and lips [3].

If universal biomechanical constraints seem to shape the child's first productions, language-specific influences have also been observed, however. Some of the "phonetically difficult" sounds are acquired relatively sooner in some languages than in others. For example, /v/ seems to be mastered earlier in Swedish, Estonian, and Bulgarian than it is in English [4]. Ingram [4] suggests this is because of the low type frequency of /v/ in English compared to the other cited languages. Therefore some language-specific differences in phonological development might be related to differences in phoneme and phoneme sequence frequency across languages (see also [5]). The ambient language would influence the child's first productions. A recent French-German comparison has even showed an influence of the surrounding speech prosody on newborns' cry melody [6].

This study is framed within the Paidologos Project (http://www.ling.osu.edu/ edwards/), a cross-linguistic investigation of phonological development. The aim is to compare the production of word-initial sequences of obstruent-vowel across many languages which contain sound sequences that differ in frequency. Children aged 2 to 5 were tested in the languages already studied (Cantonese, English, Greek, Japanese). The present study aims at extending the project to French and Drehu. Drehu is an Austronesian language, with around 15000 speakers, and is mostly spoken on Lifou Island in New Caledonia. Drehu displays a rich consonant inventory. Although French is quite present in the environment of Drehuacquiring children, Drehu is the dominant language at home and at school on Lifou Island [7].

We first analysed children production according to the frequency data in French and Drehu. Then we compared the production scores of French- and Drehu-acquiring children on similar word and non-word repetition tasks.

\section{CORPUS}

Monolingual French-acquiring children and Drehuacquiring children in bilingual French-Drehu environment (referred to as "bilingual children" for the sake of brevity) have been recorded in word and non-word repetition tasks. Eight groups of about 20 French-acquiring children from 2 to 5 years old were recorded, as well as 3 groups of about 20 Drehu-acquiring children, aged 3 to 5 . The children had to repeat a list of words in their mother tongue (in French for the "monolingual" children and in Drehu for the "bilingual" ones) and a list of typical French non-words. The words and non-words started with one of the consonants studied in the project. The children were seated in front of a computer and saw pictures of the pronounced words and non-words. The words and nonwords had been previously recorded by two female native speakers in a child-directed speech style. The instruction was to repeat the sound. A native speaker of French (first author) and a native speaker of Drehu transcribed the data. 
For words, in French, the consonants were: /t/, /d/, /k/, /g/, /s/, /S/, /t $/, / \mathrm{z} /, / \mathrm{n} /, / \mathrm{tw} /$ and $/ \mathrm{kw} /$. They were followed by:

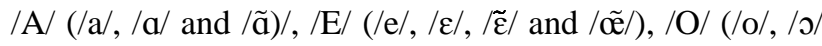
and $/ \tilde{\mathrm{o}} /), / 8 /$ (/ø/ and /œ/), /i/ and /y/. The words were as frequent as possible. For some consonants, (like $/ \mathrm{t} \mathrm{f} /$ for instance), the words were sometimes not so frequent. In Drehu, for words, the consonants were $/ \mathrm{t} /, / \mathrm{d} /, / \mathrm{k} /, / \mathrm{g} /, / \mathrm{t} \mathrm{d} /$, /d $3 /, / \theta /, / \delta /, / x /, / s /$ and /z/, followed by /a/, /i/ and /u/.

The non-words were built so as to be typical of French. They followed average frequency of syllable sequences in French. The consonants used belonged to the phonological systems of both French and Drehu. Since the frequency of these consonants are not similar in French and Drehu, this allowed us to compare production on phonemes that are rare in French but frequent in Drehu, and reciprocally. Eleven consonants were tested: /d/, /dz/, /d $3 /, / \mathrm{g} /, / \mathrm{k} /, / \mathrm{kw} /, / \mathrm{t} /, / \mathrm{t} \mathrm{j} /, / \mathrm{tw} /, / \mathrm{z} /, / 3 /$.

For the two languages, the transcriptions only concerned the word-initial consonant-vowel sequence. The transcriptions were both phonological (success or failure on the repetition of the consonant and the vowel) and phonetic (detailed coding of the type of error).

\section{ANALYSIS OF CONSONANT PRODUCTIONS ACCORDING TO THE INPUT}

\subsection{Methods}

The data obtained in word repetition were first compared with the frequency data. Some studies suggest that frequency data on phonemes can vary according to the register. Typical input to children may differ from adult lexicon. We have therefore used frequency data that were obtained from recordings of adults speaking to 2-year olds in French and in Drehu. More information on these corpora and their analyses is given in [8]. Correlation coefficients have been calculated on the 11 pairs of data. Each pair consists of the score of correct consonant production and the consonant frequency in the language.

\subsection{Results}

French - Figure 1 shows the correlation between percent correct repetition of word-initial consonants and consonant frequency in French for the youngest children in this study (20 children aged 2 years to 2 years 5 months). The two variables are highly correlated (Pearson correlation: 0.81 , significant). It should be noted that for children aged 3 years to 3 years, 5 months, the correlation falls to 0.77 and to 0.60 for children aged $31 / 2$ years to 3 years, 11 months. Figure 2 shows that at 5 years $(20$ children aged $51 / 2$ years to 5 years, 11 months), the input frequencies do not explain the scores obtained in word repetition in French (correlation .51, non significant).

Drehu - Figure 3 shows the correlation between percent correct repetition of word-initial consonants and consonant frequency in Drehu for 16 children aged 3 years to 3 years 11 months. The correlation is quite high (0.67, significant). Figure 4 shows that at the age of 5, just like in French, the correct productions are less correlated with the input frequencies (correlation 0.63, significant).

It can thus be observed that at the ages of 2 and 3, children consonant production is quite correlated with the frequency in the ambient language; later, when children have a good mastery of their mother tongue, ambient language influence is less obvious. The correct production scores are then higher than $70 \%$ for French-acquiring children, and $60 \%$ for Drehu-acquiring children.

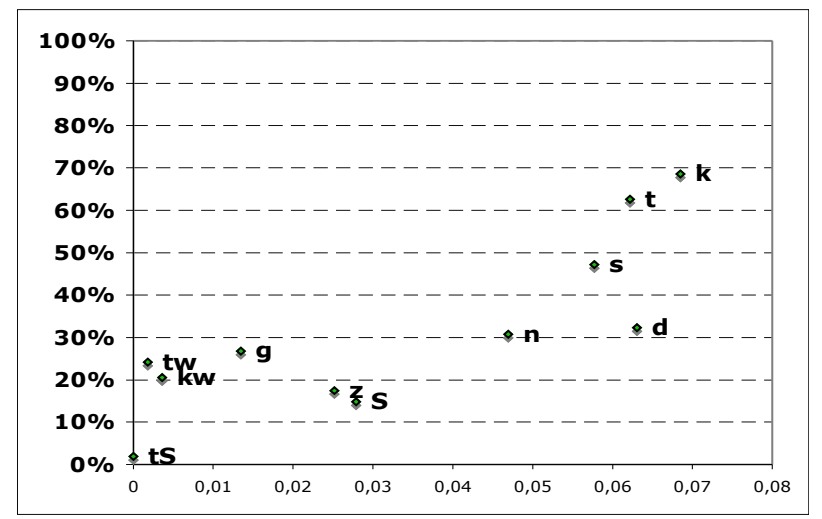

Figure 1: Correlation between correct score and input frequency in children aged 2 yrs to 2 yrs, 5 mos in French (S: $/ \mathrm{S} / \mathrm{tS}: / \mathrm{t} /$ ).

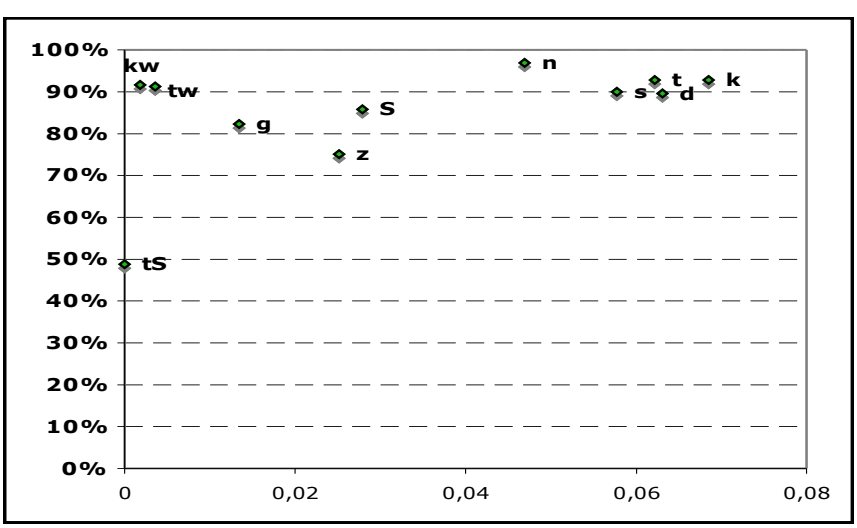

Figure 2: Correlation between correct score and input frequency in $5 \frac{1}{2}$ to 5 years, 11 months olds in French.

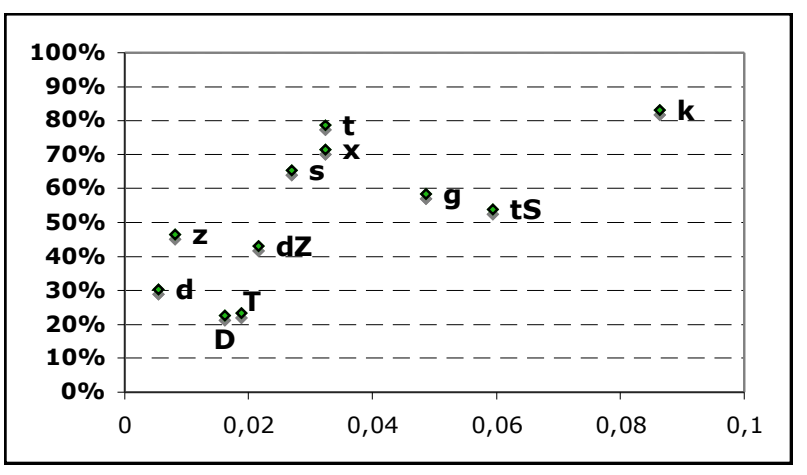

Figure 3: Correlation between correct score and input frequency, 3 year olds, in Drehu (tS : /t $\left.\int /, \mathrm{dZ}=/ \mathrm{d}_{3} /, \mathrm{T}=/ \theta /, \mathrm{D}=/ / /\right)$. 


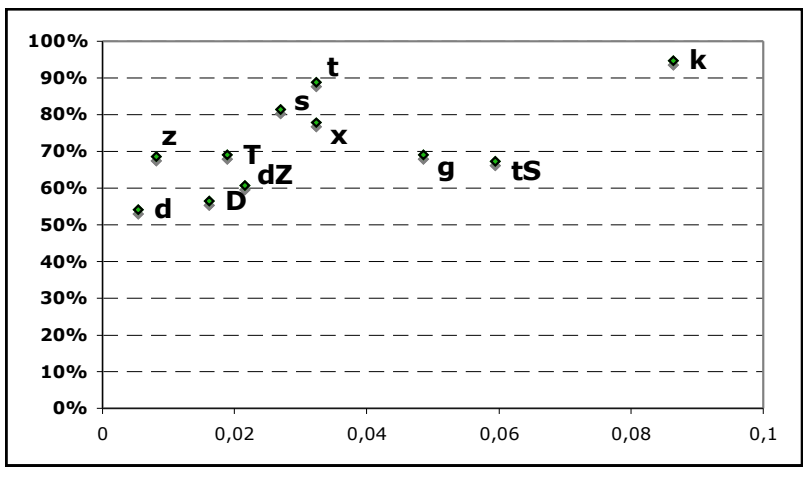

Figure 4: Correlation between correct production and input frequency in children aged 5 years in Drehu.

\section{COMPARISON BETWEEN FRENCH AND DREHU NON-WORD REPETITION TASKS}

French and Drehu children were tested on the same nonword repetition task. These data are used to compare the two groups of children with identical repetitions.

\subsection{Methods}

To compare the two groups of children, we grouped together all the 3-year old French-acquiring children, and did the same for the 4- and 5-year olds. The 2-year old French children have not been selected for this study because they were not able to do this non-word repetition task. We therefore analysed the productions of 164 children (116 monolinguals and 48 bilinguals.)

\subsection{Results for the consonants}

An ANOVA shows that the age factor is significant $(F(2,316)=29.88 \mathrm{p}<.001)$ but not language $(\mathrm{F}(1,158)=$ $3.01, \mathrm{p}=.085$ ). As shown in Figure 5, correct production gradually increases from 3 to 5 years and exceeds $50 \%$ at 5 years for the 11 consonants tested.

Figure 6 presents the results obtained in non-word repetition for the initial phonemes $/ \mathrm{k} /, / \mathrm{g} /, / \mathrm{t} /$ and $/ \mathrm{d} /$. Comparisons between these consonants are interesting because different trends were obtained for them depending on the language (for example $/ \mathrm{t} / \mathrm{is}$ better produced than $/ \mathrm{k} /$ in English but it is the opposite in Japanese). The results of the statistical analysis on our data show that the effect of language is not significant for these phonemes, except for /t/ which is better pronounced by monolinguals $(\mathrm{F}(1,158)=6.38 ; \mathrm{p}=.012)$. Yet $/ \mathrm{t} /$ is more frequent in French than Drehu. We can also note that $/ \mathrm{k} /$ reaches over $70 \%$ success even at an early age, contrary to data in the literature, where it is considered as a "difficult" phoneme [1]. This result is similar to what was observed for Japanese [9] and can be explained by the fact that $/ \mathrm{k} /$ is very common in both French and Drehu.

Figure 7 provides the results of non-word repetition for $/ \mathrm{t} / /$ and $/ \mathrm{d}_{3} /$, frequent in Drehu and rare in French, and $/ 3 /$ and $/ z /$ quite common in French and rare in Drehu. The effect of language is significant for $/ \mathrm{t} f /(\mathrm{F}(1,158)=4.86 \mathrm{p}$ $=.029)$ and $/ \mathrm{d}_{3} /(\mathrm{F}(1,158)=4.75 \mathrm{p}=.031)$ : bilinguals have better scores. The frequency of a phoneme in a language thus seems to have an impact on its production.

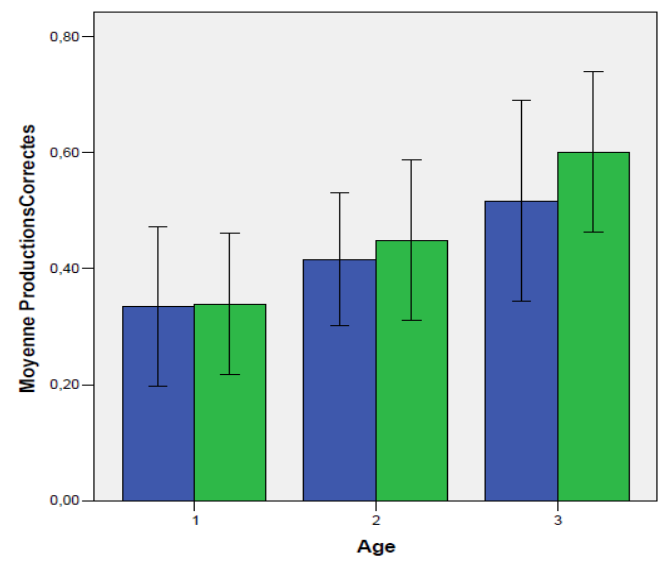

Figure 5: Repetition of «French» non-words in Drehu-French bilingual children $(\mathrm{D}$, left) and monolingual French $(\mathrm{F}$, right) at 3 years (1), 4 (2) years and 5 years (3): means of correct repetitions +- 1 standard deviations.

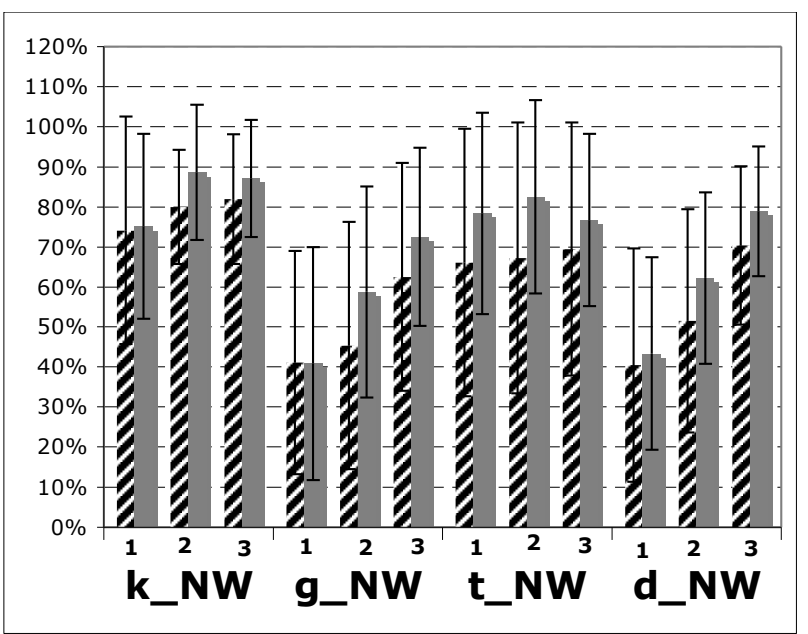

Figure 6: Correct repetition of initial consonants $/ \mathrm{k} /, \mathrm{g} / \mathrm{g} / \mathrm{t} / \mathrm{t}$ and $/ \mathrm{d} /$ in non-words (NW), with standard deviation. 1: age 3, 2: age 4, 3: 5 year olds. Hatched bar: Drehu ; gray: French.

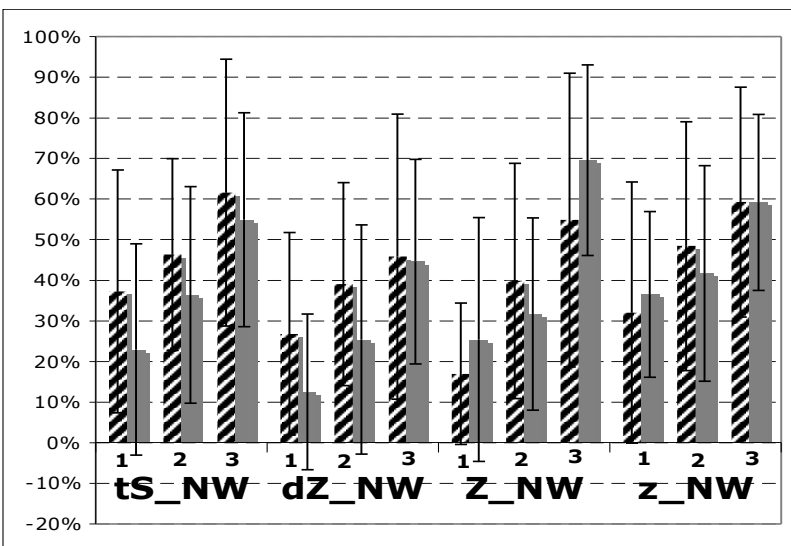

Figure 7: \% of correct repetitions of initial consonants $/ \mathrm{t} \mathrm{f} /(\mathrm{tS})$, $/ \mathrm{d}_{3} /(\mathrm{dZ}), / 3 /(\mathrm{Z})$ and $/ \mathrm{z} /$ in non-words, with one std deviation. 1 : 3 yrs, 2: 4 yrs, 3: 5 yrs. Hatched: Drehu; gray: French. 


\subsection{Results for vowels}

At 3 years, /A/ is better produced by monolinguals than bilinguals $(\mathrm{t}(42)=3.042, \mathrm{p}<.05)$; the production of the other vowels is comparable from one group to another (Figure 8). At the age of $4, / \mathrm{A} /$ and $/ \mathrm{i} /$ are better produced by the group of monolinguals $(/ \mathrm{A} / \mathrm{:} \mathrm{t}(44)=2.642, \mathrm{p}<.05$; /i/: $\mathrm{t}(44)=3.625, \mathrm{p}<.05)$. Finally, at the age of 5 , only /i/ is better produced by the monolinguals $(\mathrm{t}(45)=3.716, \mathrm{p}$ <.05). Figure 9 shows vowel frequencies in initial CV sequences in the Drehu input: / $\mathrm{i} /$ is rare. In French (Figure 10), our data show that /i/ has middle range frequency, which may explain the better production scores compared to Drehu. It should be noted that the 4 vowel groups were not produced in similar contexts: some were preceded by frequent consonants in French, others by frequent consonants in Drehu, or other. This may explain the fact that /A/, for instance, yields better production scores in French, although it is quite frequent in both languages.

\section{DISCUSSION AND CONCLUSION}

The initial phonological skills in young children (2-3 years) appear to be strongly correlated with the frequency in the input data. For our group of young French children, this correlation is very strong, and it is also quite strong for our group of Drehu-French bilingual children. As expected, these correlations decrease when the children are older ( 5 years) in the two groups considered. There is some evidence that bilingual children have sometimes a delay in lexicon acquisition. It is also known that phonological skills are associated with increased lexicon size. Still, in our non-word repetition test, children from both groups did not differ in their scores for initial consonants. Monolingual and bilingual children do display some differences, however, when phonemes are compared in detail. The phonemes that are not frequent in French and more frequent in Drehu $\left(/ \mathrm{t} f /\right.$ and $\left./ \mathrm{d}_{3} /\right)$ are better repeated by the bilinguals. The opposite is found for /d/ and /i/ in French. Thus, Drehu "bilingual" children are influenced by the input in Drehu, even if they probably also receive some input in French. All together, our results suggest that the productions of young children are highly influenced by the ambient language.

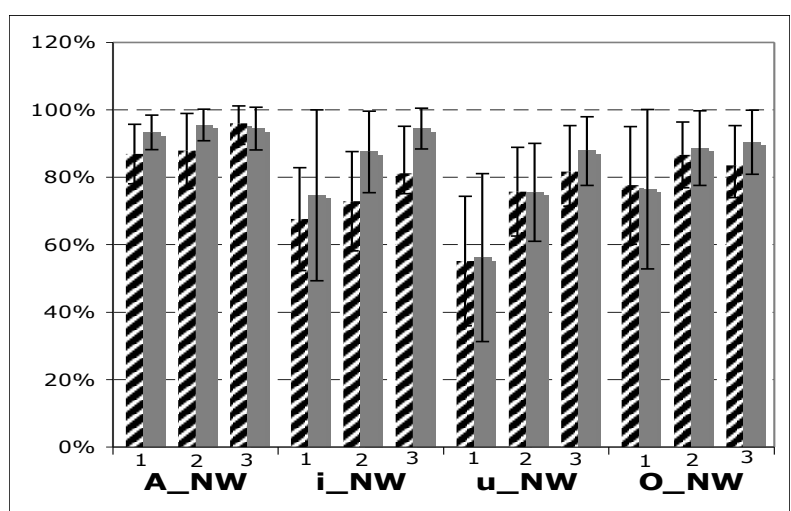

Figure 8: $\%$ of correct repetitions of the vowel following the initial consonant in non-words (NW) with a standard deviation. 1: 3 years, 2: 4 years, 3: 5 years. Hatched: Drehu; gray: French.

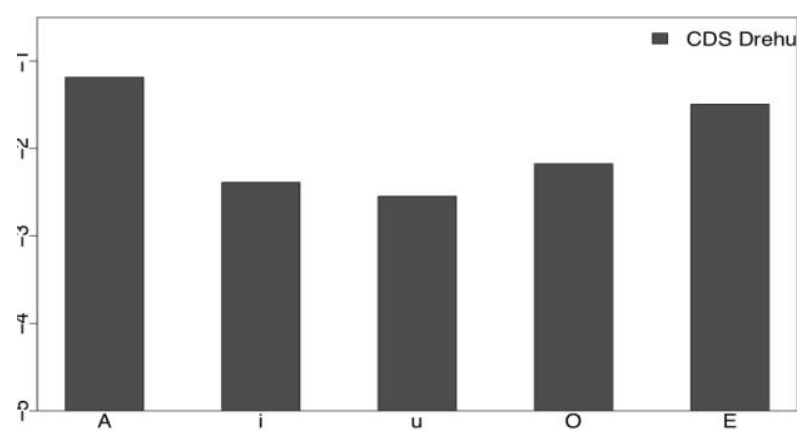

Figure 9: Vowel frequency in word-initial CV context in the Drehu input. /i/ is not frequent.

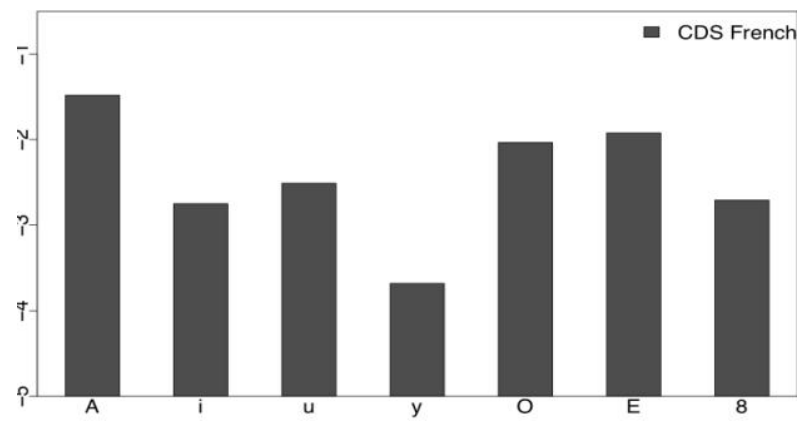

Figure 10: Vowel frequency in word-initial CV context in the French input. /i/ has middle-range frequency.

\section{ACKNOWLEDGEMENTS}

We thank F. Wacalie, N. Henesewene for the Drehu transcriptions, and M. Beckman, A. Vilain for their comments.

\section{REFERENCES}

[1] Jakobson, R. (1941/1968). A. R. Keiler, Child language, aphasia, and phonological universals. The Hague: Mouton.

[2] Hua, Z. \& Dodd, B. (2000). The phonological acquisition of Putonghua (Modern Standard Chinese). J. Child Lang., 27, 342.

[3] Davis, B.L., MacNeilage, P.F. \& Matyear, C. Acquisition of serial complexity in speech production: A comparison of phonetic and phonological approaches to first word production. Phonetica, 2002, 59, 75-107.

[4] Ingram, D. (1988). The acquisition of word-initial [v]. Language and Speech, 31, 77-85.

[5] de Boysson-Bardies, B., Vihman, M., Roug-Hellichius, L., Durand ,C., Landberg, I. \& Arao, F. (1992). Material evidence of infant selection from the target language. A crosslinguistic phonetic study. Phonological development: models, research, implications. C. A. Ferguson, L. Menn, C. StoelGammon (eds.), York Press. 369-391.

[6] Mampe, B., Friederici, A. D., Christophe, A. \& Wermke, K. (2009). Newborns' Cry Melody Is Shaped by Their Native Language. Current Biology, 19, 1-4.

[7] Moyse-Faure, C., (1983). Le drehu, Langue de Lifou (Iles Loyauté). Paris-SELAF, 17-31.

[8] Monnin, J. \& Lœvenbruck, H. (2008). Influence des fréquences lexicales des langues française et drehu sur l'acquisition des consonnes initiales de mots. Proc. of XXVIIèmes JEP, Avignon.

[9] Beckman, M. E., Yoneyama, K., \& Edwards, J. (2003). Language-specific and language universal aspects of lingual obstruent productions in Japanese-acquiring children. J. of the Phonetic Society of Japan, 7, 18-28. 